\title{
Alcohol Use during Pregnancy and Related Risk Factors in Korea
}

\section{So Hee Lee ${ }^{1}$ \\ Seung Ju Shin ${ }^{2}$ \\ Seong-Du Won ${ }^{3}$ \\ Eun-Ju Kim ${ }^{4}$ \\ Dong-Yul Oh${ }^{4} \bowtie$}

1Department of Psychiatry, National Medical Center, Seoul, 2Department of Gynecology and Obstetrics,

Kangnam CHA General Hospital,

College of Medicine,

CHA University, Seoul,

${ }^{3}$ Department of Clinical Psychology,

Keyo Hospital, Uiwang,

${ }^{4}$ Department of Psychiatry,

Myongji Hospital, College of Medicine Kwandong University, Goyang, Korea

\footnotetext{
$\triangle$ Correspondence

Dong-Yul Oh, MD, PhD

Department of Psychiatry,

Myongii Hospital, College of Medicine,

Kwandong University,

Hwajeong-dong, Deogyang-gu,

Goyang 421-270, Korea

Tel +82-31-810-5114

Fax +82-31-962-4902

E-mail dongyulo@chol.com

(c) This is an Open Access article distributed under the terms of the Creative Commons Attribution Non-Commercial License (http://creativecommons.org/licenses/by-nc/3.0) which permits unrestricted non-commercial use, distribution, and reproduction in any medium, pro-
} vided the original work is properly cited.
Objective The number of Korean women of childbearing age who drink alcohol and binge drink has increased remarkably in recent years. In the present study, we examined self-reported rates of alcohol use before and during pregnancy and identified maternal characteristics associated with drinking in pregnancy.

Methods One thousand pregnant Korean women who visited the Department of Obstetrics and Gynecology $(\mathrm{OB} / \mathrm{GYN})$ completed a self-administered questionnaire that sought information on their demographic characteristics and incorporated features of the Alcohol Use Disorder Identification Test (AUDIT)-C to investigate their use of alcohol, including binge drinking, during three time periods ("in the year before this pregnancy," "during this pregnancy," and "in the previous 30 days").

Results Of these participants, $16.4 \%$ reported using alcohol during their pregnancy, $12.2 \%$ had used alcohol in the previous 30 days, and $1.7 \%$ reported binge drinking during their pregnancy. In the year before pregnancy, $77.1 \%$ had used alcohol, and $22.3 \%$ had binge drunk. The group using any amount of any alcohol during pregnancy showed a lower educational level, a lower rate of planned pregnancy, a lower level of knowledge relating to the risks of drinking alcohol during pregnancy, and a higher frequency of alcohol drinking in the year before pregnancy when compared with the abstinent group. Low educational level and unplanned pregnancy were revealed to be significant risk factors for alcohol consumption in pregnant women.

Conclusion This is the first study to examine any alcohol and binge alcohol drinking during pregnancy in Korea. Clinical attention and monitoring system on alcohol use during pregnancy are necessary in Korea.

Psychiatry Investig 2010;7:86-92

Key Words Pregnancy, Alcohol, Korean women, Fetal alcohol syndrome.

Received: November 27, 2009 Revised: February 15, 2010 Accepted: March 17, 2010

Available online: April 6, 2010

\section{Introduction}

Recently, Korean society has experienced a dramatic increase in problems relating to alcohol use, including alcohol use among women. Following Confucian principles, traditional Korean society allowed drinking for men, but not for women. However, as society has changed, contemporary women do drink, and they are beginning to drink at younger ages and consume larger amounts of alcohol than in previous generations. The frequency of 'any use' of alcohol among women has increased from $32 \%$ in 1989 to $80 \%$ in 2007 according to National statistics. ${ }^{1}$ Particularly conspicuous is the increase in rates of binge drinking, defined as the consumption of five or more drinks on a single occasion..$^{2}$ In the past, men's drinking rate was much higher than women's, but this gap is now decreasing. Alcohol use is highest amongst those aged in their 20 s and gradually diminishes with increasing age. ${ }^{1}$ Ninety-two percent of people in their $20 \mathrm{~s}, 91 \%$ of those in their $30 \mathrm{~s}$, and $79 \%$ of those in their 40 s report any use of alcohol during their lifetime. Alcohol consumption among women of childbearing age (18-44) is noteworthy. A self-report study on the frequency of alcohol use in the past year among Korean women aged from their 20 s to their 40 s showed that $48.6 \%$ of those in their $20 \mathrm{~s}, 34 \%$ of those 
in their $30 \mathrm{~s}$, and $37.6 \%$ of those in their $40 \mathrm{~s}$ drank twice or more per month. ${ }^{1}$ Furthermore, self-report of the frequency of binge drinking in the past year revealed that $52.1 \%$ of those in their $20 \mathrm{~s}, 24.6 \%$ of those in their 30 s, and $25.9 \%$ of those in their 40 s binge drank once or more per month. ${ }^{1}$ Alcohol consumption among women who are pregnant or who might become pregnant appears, therefore, to be a serious issue that can no longer be overlooked in Korea.

Alcohol is a teratogen, and prenatal exposure to alcohol can cause a variety of problems known as fetal alcohol spectrum disorders (FASDs). The most severe form of FASD, fetal alcohol syndrome (FAS), is characterized by abnormal facial features, growth deficiencies, and problems in the central nervous system (CNS). People with FAS might have a range of learning and behavioral problems, and people exposed to alcohol prenatally are at risk of developing disorders relating to alcohol and other drug use later in life. ${ }^{3}$

It has been reported that up to 1 in 100 children in the United States (US) is born with FASD. ${ }^{4}$ Furthermore, 0.5 to 2.0 children in 1,000 are diagnosed with FAS in the US. ${ }^{5}$ The highest fetal alcohol syndrome rate was documented in a South African community in Western Cape Province where FAS was reported to affect 40.5 to 46.4 children per 1,000 in the 5-9-yearold age group. ${ }^{6}$ Many people in the Western Cape are involved in growing grapes and producing wine, and this has influenced their regional drinking patterns. For several centuries, wine was distributed among and consumed daily by workers as partial payment for labor. ${ }^{6}$ Although some sporadic case reports have examined FAS or FASD in Korea, no attempt has yet been made to investigate FAS prevalence rates or rates of alcohol drinking during pregnancy. ${ }^{7-13}$ All mothers of FAS or FASD children in these case reports consumed alcohol excessively during their pregnancies. ${ }^{7-13}$

In the present study, therefore, we examined for the first time rates of self-reported alcohol use before and during pregnancy in Korea and identified characteristics that were associated with drinking.

\section{Methods}

\section{Subjects and procedure}

One thousand pregnant women in Korea who visited the Department of Obstetrics and Gynecology (OB/GYN) at a university hospital for prenatal care were asked to fill out a survey questionnaire. Of these, 739 agreed to complete the questionnaire. Ninety-three of those who completed the questionnaire did not report on their drinking pattern, leaving 646 complete responses that were included in the analysis.

All subjects were given information about the nature of the study, and their consent was obtained by a psychiatrist. Other than those with a disorder preventing them from answering the survey questionnaire, no pregnant women were excluded from this study. The psychiatrist gave each pregnant woman the self-reporting paper questionnaires individually, and each wrote her responses in private.

\section{Survey questionnaires}

The questionnaire asked for information on participants' demographic characteristics and on their alcohol use during three time periods: "in the year before this pregnancy", "during this pregnancy", and "in the previous 30 days". Additional questions investigated participants' knowledge of the effects of alcohol on pregnancy outcomes, pregnancy history, and smoking habits.

\section{Alcohol consumption measures}

Subjects were asked about the quantity and the frequency of their drinking using Alcohol Use Disorder Identification Test (AUDIT)-C, ${ }^{14}$ a brief screening instrument that consists of the first three questions of the AUDIT: 1) frequency of alcohol drinking (any kind of alcoholic beverage), 2) quantity of alcohol consumed (typical number of drinks per day when alcohol is used), and 3) frequency of binge drinking ( $\geq 5$ standard drinks on one occasion). We used the Korean language version of AUDIT-C, and its reliability and validity had previously been demonstrated. ${ }^{15}$ A standard drink in this study was defined as $10 \mathrm{~g}$ of ethanol. All women who reported any drinking were asked to describe their beverage-specific alcohol use. They reported their frequency of drinking each type of beverage and their usual number of drinks of that beverage. AUDIT-C was repeated using the time frames: "in the year before this pregnancy", "during this pregnancy", and "in the previous 30 days".

\section{Knowledge about alcohol effects on pregnancy outcomes and the fetal alcohol syndrome}

Subjects were asked to mark the items whose probability was increased by excessive drinking during pregnancy, answering whether alcohol consumption definitely or probably increased the risk of each outcome: 1) miscarriage, 2) mental retardation, 3) low birth weight, and 4) congenital anomaly. ${ }^{16}$ Participants checked 'yes' or 'no' for each item. In addition, they were asked whether they had ever heard of FAS. ${ }^{16}$

\section{Demographic characteristics}

Subjects also answered questions on age, educational level, number of weeks of pregnancy, history of pregnancy or miscarriage, occupation, annual family income level, pregnancy planning and smoking.

\section{Statistical analysis}

Statistical Package for the Social Sciences (SPSS) 12.0 for Windows was used for statistical analysis. A frequency analysis was conducted to examine the state of alcohol drinking in pregnant women. Chi-square tests were used to evaluate dif- 
ferences in occupation, smoking status, presence of planned pregnancy, and level of recognition of FAS among women who reported alcohol use during pregnancy compared with women who abstained from alcohol use during pregnancy. When the frequency in cells was fewer than five, Fisher's exact test was used. An independent-sample t-test was performed to verify group differences in continuous variables between alcohol drinkers and total abstainers in pregnancy. Correlation analysis was conducted to evaluate correlations between alcohol drinking and post-pregnancy risk factors. A logistic multiple regression analysis was carried out to verify the predictive value of risk factors for alcohol drinking among pregnant women.

\section{Results}

\section{Demographic characteristics (Table 1)}

A total of 646 pregnant women were included in this study. Their mean age was $31.56 \pm 3.91(20-43)$ years, and their mean number of years of education was 14.96 \pm 2.17 (6-28) years. The mean duration of pregnancy at the time of the survey was $27.87 \pm 8.58$ (4-43) weeks. Forty-three (6.7\%) subjects were in the first trimester of pregnancy, $213(33.0 \%)$ were in the second trimester, and $390(60.4 \%)$ subjects were in the third trimester of pregnancy. Of these participants, 634 (98.1\%) subjects were married, and more than half $(403,62.4 \%)$ of this group were not employed.

\section{Self-reported patterns of alcohol consumption}

Alcohol use in the previous 30 days (Table 2)

A total of 643 pregnant women answered this question-

Table 1. Demographic characteristics $(\mathrm{N}=646)$

\begin{tabular}{lcc}
\hline Variables & & \\
\hline Age & $31.56 \pm 3.91$ & Range $=20-43$ \\
Education (years) & $14.96 \pm 2.17$ & Range $=6-28$ \\
Week of pregnancy & $27.87 \pm 8.58$ & Range $=4-43$ \\
1st trimester & 43 & $6.7 \%$ \\
2nd trimester & 213 & $33.0 \%$ \\
3rd trimester & 390 & $60.4 \%$ \\
Marital status & & \\
Married & 634 & $98.1 \%$ \\
Unmarried & 8 & $1.2 \%$ \\
N/R & 4 & $0.6 \%$ \\
Employment & & \\
Employed & 238 & $36.8 \%$ \\
Unemployed & 403 & $62.4 \%$ \\
N/R & 5 & $0.8 \%$ \\
\hline N/R: nonresponsive & &
\end{tabular}

N/R: nonresponsive naire $(n=643)$. On the date they responded to the questionnaire, $567(87.8 \%)$ subjects had not drunk alcohol at all in the previous 30 days, $55(8.5 \%)$ drank alcohol less than once a month, $19(2.9 \%)$ subjects drank alcohol two to four times a month, and two subjects drank two to three times a week. Analysis of the quantity drunk in the previous 30 days showed that 73 $(11.3 \%)$ subjects had consumed one to two drinks. Only three $(0.5 \%)$ subjects had consumed three to four drinks, and none had consumed five drinks or more.

Alcohol use during this pregnancy $(n=645)$ (Table 2)

Five hundred forty $(83.6 \%)$ subjects reported that they did

Table 2. Alcohol consumption of pregnant women in Korea

\begin{tabular}{|c|c|c|c|}
\hline & Variables & $\mathrm{N}$ & $\%$ \\
\hline \multicolumn{2}{|c|}{ Previous 30 days } & 643 & \\
\hline \multirow[t]{5}{*}{ Frequency } & Didn't drink & 567 & 87.8 \\
\hline & Less than 1 time a month & 55 & 8.5 \\
\hline & 2-4 times a month & 19 & 2.9 \\
\hline & 2-3 times a week & 2 & 0.3 \\
\hline & More than 4 times a week & & \\
\hline \multirow[t]{5}{*}{ Quantity } & 1-2 glasses & 73 & 11.3 \\
\hline & 3-4 glasses & 3 & 0.5 \\
\hline & 5-6 glasses & & \\
\hline & 7-9 glasses & & \\
\hline & More than 10 glasses & & \\
\hline \multicolumn{2}{|l|}{ This pregnancy } & 645 & \\
\hline \multirow[t]{5}{*}{ Frequency } & Didn't drink & 540 & 83.6 \\
\hline & Less than 1 time a month & 80 & 12.4 \\
\hline & 2-4 times a month & 23 & 3.6 \\
\hline & 2-3 times a week & 2 & 0.3 \\
\hline & More than 4 times a week & & \\
\hline \multirow[t]{5}{*}{ Quantity } & 1-2 glasses & 82 & 12.7 \\
\hline & 3-4 glasses & 8 & 1.2 \\
\hline & 5-6 glasses & 1 & 0.2 \\
\hline & 7-9 glasses & 6 & 0.9 \\
\hline & More than 10 glasses & 4 & 0.6 \\
\hline \multicolumn{2}{|c|}{ The year before pregnancy } & 645 & \\
\hline \multirow[t]{5}{*}{ Frequency } & Didn't drink & 148 & 22.9 \\
\hline & Less than 1 time a month & 231 & 35.8 \\
\hline & 2-4 times a month & 203 & 31.4 \\
\hline & 2-3 times a week & 53 & 8.2 \\
\hline & More than 4 times a week & 10 & 1.5 \\
\hline \multirow[t]{5}{*}{ Quantity } & 1-2 glasses & 220 & 34.1 \\
\hline & 3-4 glasses & 131 & 20.3 \\
\hline & 5-6 glasses & 60 & 9.3 \\
\hline & 7-9 glasses & 53 & 8.2 \\
\hline & More than 10 glasses & 31 & 4.8 \\
\hline
\end{tabular}


not drink alcohol at all. Nevertheless, 80 (12.4\%) subjects drank alcohol less than once a month, $23(3.6 \%)$ subjects drank two to four times a month, and two $(0.3 \%)$ subjects drank two to three times a week. When they drank, $82(12.7 \%)$ consumed one or two drinks on a single occasion, eight (1.2\%) had three to four drinks, and six $(0.9 \%)$ had seven to nine drinks. Four $(0.6 \%)$ subjects reported that their usual quantity was 10 drinks on a single occasion.

\section{Alcohol use in the year before pregnancy $(n=645)$ (Table 2)}

Examining the frequency and the quantity of alcohol consumption in the year before pregnancy, 148 (22.9\%) subjects drank no alcohol at all, $231(35.8 \%)$ subjects drank once or less per week, 203 (31.4\%) subjects drank two to four times per week, $53(8.2 \%)$ subjects drank two to three times per week, and
10 subjects drank alcohol four times or more per week.

The typical amounts consumed at each drinking session were one to two drinks for $220(34.1 \%)$ subjects, three to four drinks for 131 (20.3\%) subjects, five to six drinks for $60(9.3 \%)$ subjects, seven to nine drinks for $53(8.2 \%)$ subjects, and 10 or more drinks for $31(4.8 \%)$ subjects.

\section{The kind of alcoholic beverage (Table 3)}

The kinds of alcohol pregnant women mainly drank are shown in Table 3. In response to questions based on the period of one year prior to pregnancy, the soju beverage group made up $40.85 \%$ of the total alcohol consumed. However, during pregnancy and one month prior to the responding date, soju consumption accounted for $19.05 \%$ and $6.58 \%$ respectively of the alcohol consumption, showing a decline during that period.

Table 3. Beverage-specific quantity of the pregnant women in Korea

\begin{tabular}{lccccc}
\hline Type of alcoholic beverage $(\%)$ & Beer & Soju & Wine & \multicolumn{2}{c}{ Western liquors Ricewine (Makgeolli) } \\
\hline Last 30 days $(\mathrm{N}=76)$ & $56(73.68)$ & $5(6.58)$ & $15(19.74)$ & $1(1.32)$ & $1(1.32)$ \\
This pregnancy $(\mathrm{N}=105)$ & $75(71.43)$ & $20(19.05)$ & $11(10.48)$ & $1(0.95)$ & $1(0.95)$ \\
The year before pregnancy $(\mathrm{N}=497)$ & $332(66.80)$ & $203(40.85)$ & $50(10.06)$ & $2(0.40)$ & $2(0.40)$ \\
\hline
\end{tabular}

Table 4. Differences of risk factors between abstainers and drinkers during pregnancy $(\mathrm{N}=646)$

\begin{tabular}{|c|c|c|c|c|c|}
\hline Variables & & Abstainers $(\mathrm{N}=516)$ & Drinkers $(\mathrm{N}=130)$ & Statistics & $\mathrm{p}$ \\
\hline Age & & $31.60 \pm 3.86^{*}$ & $31.29 \pm 4.11$ & 0.801 & 0.423 \\
\hline Education & & $15.07 \pm 2.17^{*}$ & $14.53 \pm 2.14$ & 2.529 & 0.012 \\
\hline Income & & $4847.36 \pm 2691.13^{*}$ & $4488.79 \pm 2512.28$ & 1.251 & 0.212 \\
\hline \multirow[t]{2}{*}{ Employment } & Yes & $197(38.4)$ & $41(32.0)$ & 1.518 & 0.218 \\
\hline & No & $316(61.6)$ & $87(68.0)$ & & \\
\hline \multirow[t]{2}{*}{ Smoking } & No & $506(98.6)$ & $128(100.0)$ & 0.729 & 0.355 \\
\hline & Yes & $7(1.4)$ & $0(0.0)$ & & \\
\hline \multirow[t]{2}{*}{ Planning of pregnancy } & Yes & $361(70.2)$ & $61(47.7)$ & 22.199 & 0.000 \\
\hline & No & $153(29.8)$ & $67(52.3)$ & & \\
\hline $\begin{array}{l}\text { Frequency of alcohol drinking } \\
\text { in the year before pregnancy }\end{array}$ & & $2.72 \pm 3.43^{*}$ & $3.45 \pm 3.67$ & -2.034 & 0.042 \\
\hline Knowledge of Alcohol effects ${ }^{\ddagger}$ & & $2.18 \pm 1.05^{*}$ & $1.98 \pm 0.97$ & 2.061 & 0.041 \\
\hline \multirow[t]{2}{*}{ Miscarriage } & No & $294(57.2)$ & $79(61.7)$ & 0.685 & 0.408 \\
\hline & Yes & $220(42.8)$ & $49(38.3)$ & 0.685 & 0.408 \\
\hline \multirow[t]{2}{*}{ Mental retardation } & No & $158(30.7)$ & $49(38.3)$ & 2.334 & 0.127 \\
\hline & Yes & $356(69.3)$ & $79(61.7)$ & 2.334 & 0.127 \\
\hline \multirow[t]{2}{*}{ Low birth weight } & No & $304(59.1)$ & $80(62.5)$ & 0.351 & 0.554 \\
\hline & Yes & $210(40.9)$ & $48(37.5)$ & 0.351 & 0.554 \\
\hline \multirow[t]{2}{*}{ Birth defects } & No & $181(35.2)$ & $51(39.8)$ & 0.762 & 0.383 \\
\hline & Yes & $333(64.8)$ & $77(60.2)$ & 0.762 & 0.383 \\
\hline \multirow[t]{2}{*}{ Awareness of FAS } & Yes & $300(58.4)$ & $74(57.8)$ & 0.000 & 0.989 \\
\hline & No & $214(41.6)$ & $54(42.2)$ & 0.000 & 0.989 \\
\hline
\end{tabular}

${ }^{*}$ mean score and standard deviation, ${ }^{\dagger}$ frequency per month, ${ }^{\ddagger}$ numbers of yes to each item. FAS: fetal alcohol syndrome 


\section{Differences of risk factors between abstainers and drinkers during pregnancy}

Based on reported alcohol consumption in the previous 30 days or during this pregnancy, 516 (79.88\%) participants were classified as "abstainers," and $130(20.12 \%)$ were classified as "drinkers during pregnancy."

As shown in Table 4, the result of the analysis of differences between "abstainers" and "drinkers during pregnancy" by risk factor showed no statistically significant differences in age, family income, smoking rate, and rate of employment.

However, "drinkers during pregnancy" had a relatively lower educational level, a lower rate of planned pregnancy, and a higher frequency of alcohol use in the year before pregnancy than did "abstainers." Also, "drinkers during pregnancy" had a lower level of knowledge relating to alcohol drinking during pregnancy than did "abstainers" (based on total points for five items $)(t=2.061, \mathrm{p}=0.041)$.

\section{Correlations between variables (Table 5)}

No statistically significant correlations were found between age and either frequency or drinking or quantity of alcohol consumed during pregnancy. However, a significant negative correlation was found between age and quantity of alcohol consumed in the year before pregnancy. Thus, as the age increased, the quantity of alcohol consumed in the year before pregnancy decreased. Furthermore, a statistically significant negative correlation was found between educational level and frequency of alcohol drinking during this pregnancy, as well as between educational level and frequency and quantity of alcohol consumption in the year before pregnancy. In other words, as the educational level increased, the frequency of alcohol drinking during this pregnancy and the frequency and quantity of alcohol consumption in the year before pregnancy decreased. Statistically, planning of pregnancy was shown to have a significant negative correlation with frequency of alcohol drinking in the previous 30 days, quantity of alcohol consumption during this pregnancy, and frequency and quantity of alcohol consumption in the year before pregnancy. That is, planned pregnancy led to decreased frequency and quantity of alcohol consumption before and during pregnancy. On the other hand, frequency and quantity of alcohol consumption in the year before pregnancy had a statistically significant positive correlation with both frequency and quantity of alcohol consumption in the previous 30 days and with alcohol consumption during this pregnancy.

Table 5. Correlations matrix

\begin{tabular}{|c|c|c|c|c|c|c|c|c|c|c|}
\hline & Age & $\mathrm{Ed}$ & Income & $\mathrm{Pl}$ & $\mathrm{F} 1$ & Q1 & $\mathrm{F} 2$ & Q2 & F3 & Q3 \\
\hline Age & 1.00 & & & & & & & & & \\
\hline $\mathrm{Ed}$ & $0.12^{* *}$ & 1.00 & & & & & & & & \\
\hline Income & $0.16^{* *}$ & $0.26^{* *}$ & 1.00 & & & & & & & \\
\hline Pl & 0.04 & $0.08^{*}$ & 0.05 & 1.00 & & & & & & \\
\hline $\mathrm{F} 1$ & -0.14 & -0.07 & -0.15 & $-0.29^{*}$ & 1.00 & & & & & \\
\hline Q1 & -0.09 & -0.05 & $0.25^{*}$ & -0.21 & 0.16 & 1.00 & & & & \\
\hline $\mathrm{F} 2$ & 0.03 & $-0.27^{* *}$ & 0.01 & -0.13 & $0.69^{* *}$ & 0.04 & 1.00 & & & \\
\hline Q2 & 0.02 & -0.14 & 0.03 & $-0.33^{* *}$ & 0.16 & 0.11 & 0.13 & 1.00 & & \\
\hline F3 & -0.04 & $-0.13^{* *}$ & $-0.10^{*}$ & $-0.16^{* *}$ & $0.61^{* *}$ & $0.24^{*}$ & $0.31^{* *}$ & $0.22^{*}$ & 1.00 & \\
\hline Q3 & $-0.13^{* *}$ & $-0.20^{* *}$ & $-0.12^{*}$ & $-0.10^{* *}$ & 0.14 & $0.31^{* *}$ & 0.11 & $0.39^{* *}$ & $0.46^{* *}$ & 1.00 \\
\hline
\end{tabular}

${ }^{*} \mathrm{p}<0.05,{ }^{* *} \mathrm{p}<0.01$. Ed: education, Pl: planning of pregnancy, F1: frequency of alcohol drinking in the previous 30 days, Q1: quantity of alcohol drinking in the previous 30 days, F2: frequency of alcohol drinking during this pregnancy, Q2: quantity of alcohol drinking during this pregnancy, F3: frequency of alcohol drinking in the year before pregnancy, Q3: quantity of alcohol drinking in the year before pregnancy

Table 6. Predictors of acohol consumption during pregnancy

\begin{tabular}{lccccccc}
\hline Variables & $\mathrm{B}$ & $\mathrm{SE}$ & Wald & $\mathrm{df}$ & $\mathrm{p}$ & Odd ratios & 95\% CI for odd ratios \\
\hline Ed & -0.115 & 0.052 & 4.888 & 1 & 0.027 & 0.892 & 0.806 to 0.987 \\
P1 & -0.871 & 0.217 & 16.078 & 1 & 0.000 & 0.418 & 0.273 to 0.641 \\
F3 & 0.012 & 0.032 & 0.138 & 1 & 0.710 & 1.012 & 0.950 to 1.078 \\
Q3 & 0.072 & 0.099 & 0.530 & 1 & 0.466 & 1.074 & 0.886 to 1.304 \\
Kn & -0.145 & 0.108 & 1.803 & 1 & 0.179 & 0.865 & 0.700 to 1.069 \\
\hline
\end{tabular}

SE: standard error, CI: confidence interval, Ed: education, Pl: planning of pregnancy, F3: frequency of alcohol use in the year before pregnancy, Q3: quantity of alcohol use in the year before pregnancy, Kn: knowledge of alcohol effects 


\section{Predictors of drinkers during pregnancy (Table 6)}

The result of the verification of the predictability of alcohol drinking during pregnancy based on those variables that showed significant differences between groups (education, planning of pregnancy, frequency of alcohol drinking in the year before pregnancy, and level of knowledge about alcohol drinking in pregnancy) revealed that the model fit was statistically significant $\left(\chi^{2}=8.744, \mathrm{df}=8, \mathrm{p}=0.364\right)$. However, among the six anticipated variables listed, only level of education and planning of pregnancy significantly predicted alcohol drinking during pregnancy. Frequency and quantity of alcohol consumption in the year before pregnancy had relatively less influence on alcohol drinking during pregnancy.

\section{Discussion}

In the present study, two thirds of the subjects reported stopping drinking during pregnancy. Of participants in this study, $22.9 \%$ had already been abstainers prior to pregnancy, $60.7 \%$ had drunk alcohol before pregnancy but had stopped during pregnancy, and $16.4 \%$ continued to drink during pregnancy.

The Behavioral Risk Factor Surveillance System (BRFSS) surveys ${ }^{17}$ conducted by the Centers for Disease Control and Prevention in the US indicated that, between 1991 and 2005, $12.2 \%$ of pregnant women (about 1 in 8 ) reported any alcohol use in the previous 30 days, and $1.9 \%$ of pregnant women (about 1 in 30) reported binge drinking. So, the findings seem to be quite similar. Also, according to studies performed on three occasions in the state of Washington in the Western part of the US, the rate of alcohol drinking for the entire period of pregnancy decreased from $30 \%$ in 1989 to $12 \%$ in $2004 .{ }^{18}$ They have conducted continuous studies, case monitoring, and follow up assessments on a regional level since FAS was first recognized in the US thirty years ago.

The Korean National Health and Nutrition Examination Survey ${ }^{1}$ revealed that $80.5 \%$ of women in their $20 \mathrm{~s}, 73.2 \%$ of those in their $30 \mathrm{~s}$, and $68.5 \%$ of those in their 40 s claimed to have consumed alcohol within the past year. Seventy-seven percent of the pregnant women in our study reported any use of alcohol in the year before pregnancy. Considering that our subjects' age range was 20 to 43 , the prevalence of alcohol use found among the women appears to be compatible with that of the nationwide study.

Our findings differ from results of a Russian study ${ }^{16}$ that found a yearly rate of alcohol drinking among Russian women capable of bearing children higher than that found in our study at $95.9 \%$, but the rate of excessive alcohol drinking was lower than in our study at $18.4 \%$. According to the BRFSS investigation in the US, the monthly rate of alcohol drinking was $54.2 \%$, ${ }^{19}$ and the rate of excessive alcohol drinking was $15.5 \%$, which is lower than the findings in this study. ${ }^{20}$

We used AUDIT-C because AUDIT is one of the most wide- ly used screening tools in Korea. However, AUDIT-C has several disadvantages. AUDIT-C has not been well evaluated in terms of its use in prenatal settings. ${ }^{21} \mathrm{~A}$ safe cut-off point is not yet established in pregnant women. AUDIT-C has been found to be less sensitive to female alcohol use disorders than the TWEAK and less sensitive to pre-natal alcohol consumption than T-ACE. However, it was not used as a screening tool in this study and had the advantage of being a short, easy, and useful way to obtain information about quantity and frequency of alcohol consumption. AUDIT-C is also known to be approximately equal in accuracy to the full AUDIT. ${ }^{22}$

Unplanned pregnancy was one of the risk factors for drinking during pregnancy in the present study. Encouraging drinking women to use effective contraceptive measures, therefore, seems important for reducing unintended or unplanned pregnancies.

Frequency and quantity of alcohol use in the year before pregnancy had a positive correlation with use during pregnancy, according to our results. Binge drinking in the preconception period is known to be associated with unintended pregnancies. Therefore, all women of childbearing age should be screened for drinking and educated about the potential risks to the fetus of alcohol use during pregnancy. Although about $50 \%$ of pregnant women in this study had heard of FAS, the drinker group had a significantly lower level of knowledge about drinking in pregnancy.

This study has several limitations. First, the sample used was not randomly selected from all socio-demographic groups, but was obtained by selecting a location where large numbers of pregnant women could be found. It was not designed to be a prevalence study, but as the demographic data show, the subjects participated in this study were not particularly young, and they were largely in the middle class and relatively highly educated. So, women at high risk might not have been included. Although the study results cannot be generalized, they may provide a limited reflection of the extent of the problem of alcohol use in pregnancy and may identify categories of women who are most likely to be problem drinkers.

Second, data were obtained by self-report, and some women may have under-reported their alcohol use. To prevent this, it would be helpful to combine the self-report information with other more objective measures. However, as with any other test, ethical considerations need to be taken into account. Because more than half of the participants were in their 3rd trimester, even though they were asked about their drinking during the entire pregnancy, their answers might have referred to the period after their recognition of their pregnancy. Therefore, alcohol use prior to their awareness of pregnancy recognition might have been missed.

Third, the rate of refusal to complete the questionnaire was $26.1 \%$. Most women who refused said they were busy and did not clearly explain the reason for the refusal. In the process 
of obtaining written consent from these subjects, pregnant women who consumed relatively large amounts of alcohol did not want to reveal their names. Furthermore, pregnant women with any suspicion of fetal deformity in the basic prenatal tests tended to refuse the survey questionnaire.

In conclusion, we performed an assessment of alcohol consumption in pregnant Korean women. Of the respondents, $16.4 \%$ reported use of alcohol during pregnancy, and $12.2 \%$ reported use of alcohol in the previous 30 days. Binge drinking during pregnancy was reported by $1.7 \%$. Low educational level and unplanned pregnancy were found to be risk factors for alcohol consumption in pregnant women. Future studies on the prevalence of FAS or FASD should be carried out in Korea.

\section{-Acknowledgments}

We thank Dr. Edward P. Riley and Dr. Christina Chambers for their comments on this study.

This study was supported by a grant from the National Center for Mental Health Research \& Education, the Seoul National Hospital, Korea (09-206A-01).

This study was presented at the 1st congress of Asia-Pacific Society for Alcohol and Addiction Research, Seoul, Korea, Nov. 12-14, 2009.

\section{REFERENCES}

1. Ministry for Health, Welfare and Family Affairs, Korea Center for Disease Control and Prevention. The Fourth (2007) National Health and Nutrition Examination Survey. 2008 Dec.

2. Ministry for Health, Welfare and Family Affairs, Korea Center for Disease Control and Prevention. In-depth Analyses of the Third National Health and Nutrition Examination Survey: the health interview and health behavior survey part. $2007 \mathrm{Apr}$.

3. Bertrand J, Floyd RL, Weber MK, O'Connor M, Riley EP, Johnson KA, et al. National Task Force on FAS/FAE. Fetal Alcohol Syndrome: Guidelines for Referral and Diagnosis. Atlanta, GA: Centers for Disease Control and Prevention; 2004.

4. Sampson PD, Streissguth AP, Bookstein FL, Little RE, Clarren SK, Dehaene $P$, et al. Incidence of fetal alcohol syndrome and prevalence of alcohol-related neurodevelopmental disorder. Teratology 1997;56: 317-326.

5. May PA, Gossage JP. Estimating the prevalence of Fetal Alcohol Syndrome. A summary. Alcohol Res Health 2001;25:159-167.

6. May PA, Brooke L, Gossage JP, Croxford J, Adnams C, Jones KL, et al. Epidemiology of fetal alcohol syndrome in a South African community in the Western Cape Province. Am J Public Health 2000;90:1905-
1912.

7. Hong KD, Yoo IC, Choi HS, Lee DH, Lee SJ. A case of fetal alcohol syndrome. J Korean Pediatr Soc 1988;31:375-380.

8. Kim EJ, Yang SM, Yun J, Lee HK, Yu YH, Lee HS. A case of fetal alcohol syndrome. J Korean Pediatr Soc 1998;41:1001-1005.

9. Kim JH, Han MK, Kim JL, Park YI, Lee JJ. A case of fetal alcohol syndrome. J Korean Child Neurol Soc 2001;9:393-397.

10. Chang JH, Namgung R, Park MS, Park KI, Lee JS, Lee C. A case of fetal alcohol syndrome with persistent pulmonary hypertension of the newborn. Korean J Pediatr 2004;47:1220-1224.

11. Cho YY, Oh HJ, Han SJ, Sung SH, Bae GH, Shon HS, et al. A case of fetal alcohol syndrome with secondary amenorrhea. J Korean Soc Endocrinol 2005;20:524-530.

12. Cho YK, Chang SD, Kim YC, Lee SY. A case of fetal alcohol syndrome with esotropia. J Korean Ophthalmol Soc 2005;46:1756-1759.

13. Bhang SY, Ahn DH, Lee YJ, An HY, Ahn JH. The first report of fetal alcohol effect in a 12 year-old child in Korea. Psychiatry Investig 2009; 6:50-53.

14. Bush K, Kivlahan DR, McDonell MB, Fihn SD, Bradley KA. The AUDIT alcohol consumption questions (AUDIT-C): an effective brief screening test for problem drinking. Ambulatory Care Quality Improvement Project (ACQUIP). Alcohol Use Disorders Identification Test. Arch Intern Med 1998;158:1789-1795.

15. Lee BO, Lee CH, Lee PG, Choi MJ, Namkoong K. Development of Korean Version of Alcohol Use Disorders Identification Test (AUDIT$\mathrm{K})$ : its reliability and validity. J Korean Academy of Addiction Psychiatry 2000;4:83-92.

16. Kristjanson AF, Wilsnack SC, Zvartau E, Tsoy M, Novikov B. Alcohol use in pregnant and nonpregnant Russian women. Alcohol Clin Exp Res 2007;31:299-307.

17. Centers for Disease Control and Prevention (CDD). Alcohol use among pregnant and nonpregnant women of childbearing age-United States, 1991-2005. MMWR Morb Mortal Wkly Rep 2009;58:529-532.

18. Grant TM, Huggins JE, Sampson PD, Ernst CC, Barr HM, Streissguth AP. Alcohol use before and during pregnancy in western Washington, 1989-2004: implications for the prevention of fetal alcohol spectrum disorders. Am J Obstet Gynecol 2009;200:278.e1-e8.

19. Tsai J, Floyd RL, Green PP, Boyle CA. Patterns and average volume of alcohol use among women of childbearing age. Matern Child Health J 2007;11:437-445

20. Tsai J, Floyd RL, Bertrand J. Tracking binge drinking among U.S. childbearing-age women. Prev Med 2007;44:298-302.

21. Sarkar M, Burnett M, Carrière S, Cox LV, Dell CA, Gammon H, et al.; Fetal Alcohol Spectrum Disorder Advisory Workgroup. Screening and recording of alcohol use among women of child-bearing age and pregnant women. Can J Clin Pharmacol 2009;16:e242-e263.

22. Reinert DF, Allen JP. The alcohol use disorders identification test: an update of research findings. Alcohol Clin Exp Res 2007;31:185-199. 